\title{
A phenomenological exploration of transgender people's experiences of mental health services in Ireland
}

Running title: transgender and mental health services

Neil Delaney ${ }^{1}$ Edward McCann ${ }^{2}$

1. School of Psychology, Trinity College Dublin, Dublin, Ireland

2. School of Nursing and Midwifery, Trinity College Dublin, Dublin, Ireland

Acknowledgments: The authors would like to acknowledge the participants to this research and thank them for their input.

Conflict of Interest: The authors declare no conflict of interest.

Funding: This research has received no funding.

Ethical Approval: Ethical approval was granted by the School of Psychology Research Ethics Committee at Trinity College Dublin. Approval ID: SPREC112018-07

\section{Correspondence:}

Neil Delaney

Email: nedelane@tcd.ie

Contact number: 087-7403937 


\title{
A phenomenological exploration of transgender people's experiences of mental health services in Ireland
}

\begin{abstract}
Aim: This study sought to explore the personal experiences of transgender people with Irish mental health services.

Background: The transgender community have been identified as an underserved, underresearched community in Ireland and abroad. While there has been a surge in research carried out with the community in recent years, there is little known about the personal experiences of Irish transgender people with mental health services.
\end{abstract}

Method: Interpretative Phenomenological Analysis (IPA) was used to inform data collection and analysis of semi-structured interviews carried out with four research participants all identifying as transgender and having experienced accessing Irish mental health services.

Results: Three themes emerged; affirmative experiences, non-affirmative experiences, and clinician relationship.

Conclusion: Lack of information and non-affirmative experiences are contributing to poor clinician-patient relationships with transgender populations and impacting attrition.

Implications for nursing management: Nurse managers have a central role in supporting a transgender positive organisational approach to care by ensuring policies, care practices and the environment are supportive of sexual and gender expression by role modelling attitudes of respect and inclusivity. In order to provide appropriate and responsive services to transgender people, there needs to be in place strategies to enable the development of confident, competent and knowledgeable staff

KEYWORDS: Transgender, experience, relationship, information, nursing 


\section{Introduction}

Evidence suggests that members of the LGBT community experience higher rates of mental health issues such as depression, anxiety and suicidality compared to the general population (King et al., 2008; McLaughlin, Hatzenbeuhler, Xuan \& Connor, 2011; Rhoades et al., 2018;). While, in recent years there has been a surge in research on the LGBTQIA+ (Lesbian, Gay, Bisexual, Transgender, Queer, Intersex, Assexual amd including other sexual minorities) community, the transgender community has been declared an at-risk population (Cicero et al., 2020). According to a report published by the Transgender Equality Network, Ireland (TENI), $82 \%$ of transgender people in Ireland are living with depression, $73 \%$ are living with anxiety and 55\% felt they had experienced a mental health crisis at one point in their lives (McNeil, Bailey, Ellis \& Regan, 2013). In comparison with cisgender youth, transgender and gender non-conforming youth had more than 3.6 times the risk of suicidal ideation and 3.2 times the risk of suicide attempts (Perez-Brumer, Day, Russell \& Hatzenbuehler, 2017). It is important to note that much of the research applied to the trans community is derived from research on the wider LGBT community. The trans population is a pivotal part of the LGBT community and the notable disparity in the experiences of developing a sense of sexual orientation and developing a sense of one's own gender identity should be acknowledged. For example, Higgins et al. (2016) found that transgender (32.9\%) and intersex (42.1\%) people were more likely to report a decline in mental health in the previous five years than gay males $(21.7 \%)$, lesbian/gay females (24.4\%) and bisexuals (28.8\%). In this same study, it was the transgender and intersex parties that scored the highest scores respectively on scales measuring depression, anxiety and stress. These statistics place the transgender community firmly as an at-risk population within the context of society and the LGBT community.

While few studies exist exploring the experiences of transgender people with nurses specifically, the healthcare needs of the trans community have been well documented in the 
research abroad and in Ireland (Higgins et al., 2016; McCann \& Brown, 2018; McCann \& Brown, 2017; McNeil et al, 2013). An issue that is regularly raised is clinician knowledge and their ability to work with and understand the challenges faced by the transgender community. In 2015, the American Psychological Association published guidelines for working in a genderaffirmative way with transgender clients (Guidelines for Psychological Practice with Transgender and Gender Nonconforming People). This document noted that trans-affirmative therapy is considered best practice. These trans-affirmative guidelines are mirrored by the World Professional Association for Transgender Healthcare (WPATH) who recommend a model of informed consent when helping a transgender individual transition to their experienced gender (Deutsch \& Feldman, 2013). While this may be the case in policy, it is not the case in practice in an Irish context. Higgins et al. (2016) dedicated a section of their seminal LGBT Irelamd Report to LGBT experiences with mental health services finding that $35.1 \%$ of transgender people identified being afraid of stigma when accessing mental health services, the second highest figure behind intersex individuals (37.5\%). Transgender individuals were also the most likely group to consider services non-LGBT-friendly in comparison with other sexual minority groups $(35.5 \%)$. Transgender people find themselves at increased need of mental health services due to minority stress (Hendericks \& Testa, 2012) and because of the psychiatric model of care in place in Ireland.

Working with this population presents unique barriers to and opportunities for healthcare professionals. Nurses specifically play key roles in the support of transgender people accessing mental health services and healthcare more generally. However, the research indicates that medical practitioners including nurses can lack knowledge, education, training and personal experience in this area (Tores et al., 2015). Levesque (2013) explored nurses' knowledge, attitudes and self-efficacy when working with a transgender population using qualitative surveys. While the majority of nurse practitioners reported 'full respect' and 
'acceptance' towards the trans community, low rates of self-efficacy for providing care and no training provided specifically in this area throughout education was recorded. Similar to this study, Paradiso \& Lally (2018) found that while nurses expressed a caring, positive attitude and a wish to create a comfortable environment for their transgender clients, they felt hindered by their lack of education in the area. This research indicates that there is a gap in nursing education in this field and an interest in remedying this to provide a more inclusive healthcare environment.

The current research aimed to explore in-depth the experiences of transgender people with mental health services in Ireland. While the data collected was primarily focused on mental health practitioners, narratives pertaining to nursing naturally came to the fore. Therefore, implications for this cohort are discussed with recommendations made for development in practice.

\section{Method}

\section{Design}

Research question formulation, data collection and analysis were all informed by Interpretative Phenomenological Analysis (IPA). This methodology seeks to explore the indepth personal experiences of the participant in order to gain an understanding of how that participant makes sense of their experience (Smith et al., 1999).

\section{Participants}

Purposive, snow-ball sampling was used in this research. The transgender community can be inaccessible in part because they count for less than $1 \%$ of the population and in part because of issues of trust and safety. Four participants took part in the study. Smaller numbers of participants are common with IPA to allow for an in-depth exploration of participant 
experience and to avoid saturation (Smith, Larkin \& Flowers, 2009). Demographic information is captured in Table 1 .

**Table 1 here **

\section{Data collection}

Prior to interview, participants were asked to complete an online questionnaire collecting demographic data. Interviews were semi-structured as per the IPA process. An interview schedule was developed using the input of a transgender individual, an expert in the field of LGBT research and two experts in the field of IPA research. While an interview schedule was available, the interviews were participant-led, meaning questions were asked outside of the interview schedule based on the information provided by the participant. This allows for a more phenomenological exploration of the participant's experience. The opening statement of the interview was; 'Tell me about your experiences with Irish mental health services', with prompts such as 'tell me more about that' and 'what was that like for you' used to further explore topics.

\section{Procedures}

Upon receipt of Ethical approval, recruitment began. Participants were recruited via email. A recruitment poster was sent to LGBT resource centres, transgender support groups, LGBT safe spaces and LGBT-friendly businesses. Participants could contact the researcher via email after which the researcher would forward a participant information sheet and a consent form. Once consent had been agreed, participants decided a time and date for interview with the researcher. Two interviews took place in person and two interviews took place via Skype phone call. All interviews were audio-recorded and lasted from 45 minutes to one-hour. Once the interview had been completed, participants were thanked for their participation and offered a de-brief sheet. 


\section{Analysis}

In accordance with IPA guidelines (Smith, Flowers and Larkin, 2009) transcripts were listened to and read multiple times. Once the researcher felt they understood the data and the emotional contents of each transcript, written analysis could begin. Each transcript was analysed four times with an emphasis on different aspects of the data each time; free association to the material, descriptive and content-based material, language, and interrogative and exploratory material. Themes were elucidated from each transcript and then organised into themes based on their prominence and emotional depth.

\section{Reflexivity and Bracketing}

IPA is personal by nature to both the researcher and participant. Therefore, it is important for the researcher to acknowledge and put to one side their vested interest in any piece of qualitative research, a process commonly referred to as bracketing (Fischer, 2009). Given the identification and elimination of bias, bracketing is considered a method of confirming validity in qualitative research (Chan, Fung \& Chien, 2013). The researcher considered their position as a member of the LGBTQIA+ community both a strength and a possible conflict of interest within this research. Bracketing conversations with the supervising researcher were held throughout the undertaking of this research to ensure the validity of the study.

IPA acknowledges the inescapably significant role of the researcher, creating a doubly hermeneutic undertaking (Benson, 2013). Personal reflections were maintained throughout the research process using a reflexive journal allowing the researcher to challenge their perceptions and understandings of the findings as well as explore the content of the data collected on a personal, interrogative level. 


\section{Results}

Three themes were developed from the analysis of interview transcripts; affirmative experiences, non-affirmative experiences and clinician relationship. All themes were identified by all participants.

\section{Affirmative experiences}

Affirmative experiences with mental health services refer to the experiences of participants that encourage, rather than pathologize, their identity. Through an understanding of the trans experience, including the barriers facing the community as well as a proficient insight into the process of transition, participants felt affirmed. This was the case for Participant 1 (P1) and Participant 2 (P2), who both highlighted the benefits of working with a practitioner who knew what services to refer them to. Participant 3 (P3) met with a clinician who had a lesser understanding of what it meant to be transgender in the healthcare system. When they found a clinician who demonstrated an understanding of their needs and the system within which they were operating they experienced feelings of 'relief', 'safety' and 'comfort'. Similarly, Participant $4(\mathrm{P} 4)$ failed to find a practitioner who understood their experience in the public health system. This led them to search for a private mental health service which was more positive because of the understanding the therapist demonstrated in relation to their trans identity.

Ifeel like I have someone I can share this with, someone who understands, someone who I can relate to it in certain ways....'

P1 also experienced affirmation when their clinician described the diverse identities situated beneath the 'transgender umbrella'. P1 struggled with their identity because they felt they did not fit into the 'true trans narrative'- a narrative that insists transgender people adhere to binary standards of gender and have a pre-pubescent awareness of their experienced gender. 
'He actually said to me that there is more than one way to be trans . . and I think it was the first time I had heard any professional in any capacity say that. So, it was fantastic - it was affirming.'

\section{Non-affirmative experiences}

In contrast to affirmative experiences, non-affirmative experiences are those that do not support and maintain the phenomenology of the individual. Non-affirmative experience can be understood as misinformation, transphobic behaviours, inappropriate conduct or discriminatory biases. In relation to mental health services, a non-affirmative approach could be considered the pathologizing of the transgender identity or the treatment of transgender people in such a way that digresses the individual from their experienced gender.

An inherently non-affirmative experience, mis-gendering is the act of misinterpreting someone's gender or referring to them using incorrect pronouns. P2 gives an account of the labour they assumed after being mis-gendered by a nurse:

'I feel like it breaks down trust with them. From the get-go you realise how much emotional labour they're going to put you through...'

Mis-gendering acted as a trigger for $\mathrm{P} 2$ that 'sets the ball rolling of me completely selfsabotaging or me trying to harm myself'. $\mathrm{P} 4$ identified a number of experiences relating to a lack of knowledge on the behalf of mental health services, one of which highlighted feelings of rejection that 'deeply affected' them beyond the experience.

In some cases of non-affirmative experience, participants indicated terminating contact with a specific service. P1 found a negative change in the demeanour of their clinician after speaking with them about self-medicating with hormones leading to termination of service. P1 described their clinician's change in behaviour leading to a dysphoric reaction: 
'. . You know, that I was disgusting, that I was a freak, that I'm weird. That society is going to look at me and see some sort of 'it'. ..'

P2 experienced non-affirmation from a clinician who questioned their trans identity leading them to ask to be removed from the care of their mental health clinician, a request which was not attended to. P3 asserted their autonomy in an adverse situation when a nurse requested the name P3 used prior to realising their experienced gender. This act is known as 'dead-naming' and is considered inappropriate and invalidating by the transgender community, the LGB community and their allies.

P4 described their experience with their clinician who asked them why they cross-dress if it causes a dysphoric reaction: 'he asked me why am I still dressing up even in a minor way - with aggression all over it'. After being admitted to inpatient care and having a negative experience with their clinician who raised their voice at them, P4 discharged themselves from hospital: '. . that's when I decided I had to get out of there'.

\section{Clinician Relationship}

Clinician here refers to any healthcare professional participants encountered including nurse practitioners. Fundamental attributes contained within the clinical relationship were discussed by all four participants. Participants' experiences of the clinical relationship incorporated feelings of connection, trust, and comfort allowing for a more fulfilling relationship. Conversely, negative experiences were punctuated with inauthentic relationships from which participants gained little support.

Rapport is the positive relationship built between clinician and client. The importance of having an open space in which a client can be vulnerable was described by P4. Feeling safe 
allowed them to express their vulnerability in the therapeutic environment, something that led to deeper exploration and a stronger relationship:

'. . it's more that you're protected, and you know that . . you can bring up this vulnerable side to you'

Rapport building can be a time-consuming act, something made more arduous for transgender people who have experienced trans-negativity in the therapeutic environment. P2 spoke of struggling to find sufficient care within mental health services, having met 4 counsellors they could not build a positive rapport with.

The ability of the therapist to relate in therapy was indicated as an important factor by both P3 and P4. Through knowledge and understanding of the trans experience, P3's therapist was able to relate to their experience and thus facilitate a stronger, more enduring rapport. P4 described their experiences with a clinician who could relate as 'a certain bond' and suggested that if a clinician had experience or could relate to the trans identity, it should be stated at the outset of therapy. They also indicate factors contributing to positive rapport such as 'understanding', 'non-judgemental', and 'supportive'.

The authenticity of the clinician-service-user relationship was met both positively and negatively. Inauthentic relationships were bred often due to systemic pressure for transition related care while experiences of authentic relationships proved beneficial.

P1 spoke about the medical model currently used to assist transgender people in the process of transitioning. The system involves procuring two diagnoses of gender dysphoria (as per the Diagnostic and Statistical Manual of Mental Disorders-5), something P1 perceived as damaging to the health of the trans community (American Psychiatric Association, 2013). 
¿.. I just think the whole diagnostic model is incredibly damaging (pause). Because all that's happening is rather than what they think is ensuring treatment for the people who need it, what you're getting is people lying about their experience'

An inauthentic relationship was described by $\mathrm{P} 2$ who was given a 'brief' by a friend in advance of their gender assessment which they referred to as a kind of 'quiz'. In order to pass, their responses needed to be specific and could leave no room for confusion, thus creating an inauthentic relationship with their clinician from the outset.

\section{Discussion}

The aim of this research was to explore, in depth, the experiences of transgender people with mental health services in Ireland. The results indicated areas of potential growth and development for healthcare practitioners, including nurses, working with this cohort as well as highlighting experiences of positivity that can be reinforced in future learning and teaching. These findings are in line with similar research carried out in the United Kingdom where trans* healthcare has been deemed inadequate (Bachman \& Gooch, 2018) and Australia where the research is calling for urgent development to trans healthcare (Strauss, Cook, Winter \& Watson, 2019). The themes extracted from the data are discussed in relation to nurse practitioners and nursing managers in this section.

The first theme of 'affirmative experiences' spoke of positive encounters participants had with mental health services. Analysis of these positive experiences indicated that at their core, these were experiences of validation, understanding and affirmation. Benson (2013) demonstrated the clinician's ability to affirm their transgender client's identities through validation and affirmation. It is important for nursing managers to set standards of practice by role modelling this approach. Language is power and with the simple act of affirming a 
transgender person's experienced gender identity and adhering to their appropriate pronouns they can create more positive experiences for this community.

An understanding of the transition process, the trans identity and the challenges facing the community all contributed to better service-user experience in this research. Bockting et al. (2006) speaks of similar findings and recommends clinicians demonstrate an awareness of transgender concerns by maintaining a base of visible literature in their practice and ensuring documents are gender-inclusive (allowing for more than binary responses to gender fields, using appropriate forenames on documents etc). Nursing managers have the opportunity to cultivate understanding connections with their trans* clients by providing access to these tangible resources.

The second theme of non-affirmative experiences is punctuated by a lack of knowledge on the clinician's behalf, which led to transphobic experiences such as misgendering and deadnaming. The LGBT Ireland Report highlights a significant number of participants in the study were concerned that a lack of training and knowledge was leaving clinicians ill-equipped to adequately support those within the community (Higgins et al., 2016.) Participants identified a specific gap in gender-based knowledge, something that is mirrored in this study An informed, affirmative approach to working with transgender people is championed by the majority of healthcare organisations with guidelines for this approach being laid out by a number of professional bodies (American Psychiatric Association, 2015; British Psychological Society, 2012; World Professional Association for Transgender Healthcare, 2013). These resources are considered valuable material and have the potential to be useful for nurse managers seeking to educate themselves and their colleagues and understand how best to engage with this community. 
Non-affirmative experiences related to a lack of knowledge led to issues of trust with the clinician with participants describing an inability to maintain an open relationship with therapists and nurses alike. This was further developed in the third theme of clinician relationship. Discrepancies in knowledge hurt clinicians' ability to create and maintain honest, open, trusting relationships with their service-users. This finding is in-line with recent Canadian literature in this area (Weir \& Piquette, 2019). Low quality relationships were bred under the pressure of the diagnostic model which in the case of this research led to clinicianservice-user relationships underlined by dishonesty and inauthenticity. Lev (2004) speaks of a similar phenomenon, highlighting the position of the healthcare worker as gatekeeper to gender-related supports. The author notes that this position leads to distrust in the clinical relationship as transgender clients may not speak of the issues they actually face. It is therefore evident that knowledge of the transgender experience is not only imperative for clinical practice, but is important in developing trusting relationships, something nursing managers should be encouraging and empowering their team members to achieve with all patients.

A phenomenon noted by all participants was their attrition from service after a nonaffirming experience. Similar findings are indicated in research relating to minority groups generally (Sperber, Landers \& Lawrence, 2005). More specifically McCullough et al. (2017) noted transgender participants to their study also prematurely terminated their relationship with their counsellor after a negative experience. While attrition from service can be considered an assertion of autonomy in the face of inimical circumstances, something which could be considered an act of resilience, the impact of this in reality is that transgender people are losing out on opportunities for healthcare support. This could potentially mean loss of or delayed access to important treatment including transition focused intervention. Nurse managers can position themselves to prevent this attrition by making services more comfortable and affirming for members of the transgender community. 


\section{Limitations}

The term 'transgender' was used for advertising purposes for this research. Upon reflection and having spoken with participants, it would have been more inclusive and beneficial to have used the terms 'transgender and gender nonconforming' or 'TGNC'. This term acknowledges the diversity of identity living beneath the transgender umbrella and would have attracted a broader participant base.

\section{Conclusions}

While this research is focused primarily on mental health services and clinicians, there are a number of findings that are applicable to the field of nursing management specifically in the areas of education, research and practice.

Modules including information on the transgender community should be included in nursing curricula and supported by nursing management. It is recommended that these modules are informed by best practice guidelines which support a gender-affirmative approach to the care of transgender populations. Future research should explore the feasibility of including transgender specific education into the curriculum for training nurses in an Irish context as well as supporting nurse managers in this area.

\section{Implications for Nursing Management}

There is a growing interest in the health and social care needs of people who identify as transgender and this has become increasingly apparent through the issues that have emerged in this study. Organisations and nurse leaders will need to support practitioners in terms of practice, education, and research. The challenge is for service to work collaboratively with trans* communities to develop and implement effective strategies and interventions that meet the identified needs. Adequate resources must be provided to support and enable future practice development initiatives and the delivery of appropriate services that address equality, diversity 
and social inclusion issues. Nurse managers have a central role in supporting a transgender positive organisational approach to care by ensuring policies, care practices and the environment are supportive of sexual and gender expression by role modelling attitudes of respect and inclusivity. In order to provide appropriate and responsive services to transgender people, there needs to be in place strategies to enable the development of confident, competent and knowledgeable staff. 


\section{References}

American Psychiatric Association (2013). Diagnostic and statistical manual of mental disorders (DSM-5®). American Psychiatric Pub.).

American Psychological Association. (2015). Guidelines for Psychological Practice with

Transgender and Gender Nonconforming People. American Psychologist, 70 (9), 832

864. doi:10.1037/a0039906

Bachmann, C. L., \& Gooch, B. (2018). LGBT in Britain: Trans Report. London: Stonewall.

Benson, K. E. (2013). Seeking Support: Transgender Client Experiences with Mental Health $\begin{array}{lllll}\text { Services. Journal } & \text { Feminist }\end{array}$ doi:10.1080/08952833.2013.755081

Bockting, W. O., Miner, M. H., Swinburne Romine, R. E., Hamilton, A., \& Coleman, E. (2013). Stigma, mental health, and resilience in an online sample of the US Transgender population. American journal of public health, 103(5), 943-951. doi: 10.2105/AJPH.2013.301241

British Psychological Society (2012). Guidelines and literature review for psychologists working therapeutically with sexual and gender minority clients. Leicester, UK: British Psychological Society.

Chan, Z. C. Y., Fung, Y., Chien, W. (2013). Bracketing in Phenomenology: Only Undertaken in the Data Collection and Analysis Process? The Qualitative Report, 18(59), 1-9

Cicero, E. C., Reisner, S. L., Silva, S. G., Merwin, E. I., \& Humphreys, J. C. (2019). Healthcare experiences of transgender adults: an integrated mixed research literature review. ANS. Advances in Nursing Science, 42(2), 123. 
Deutsch, M. B., \& Feldman, J. L. (2013). Updated recommendations from the world professional association for transgender health standards of care. American Family Physician, 87(2), 89-93.

Fischer, C. T. (2009). Bracketing in qualitative research: Conceptual and practical matters. Psychotherapy Research,19(4-5), 583-590. doi:10.1080/10503300902798375

Hendricks, M. L., \& Testa, R. J. (2012). A conceptual framework for clinical work with Transgender and gender nonconforming clients: An adaptation of the Minority Stress Model. Professional Psychology: Research and Practice, 43(5), 460-467. doi:10.1037/a0029597

Henkin, W. A. (2008). Coming out trans: Questions of identity for therapists working with transgendered individuals (trans identity from the queer perspective). Electronic Journal of Human Sexuality, 11.

Higgins, A., Downes, C., Murphy, R., Sharek, D., DeVries, J., Begley, T., . . Smyth, S. (2016). The LGBTIreland report: The national study of the mental health and wellbeing of lesbian, gay, bisexual, transgender, and intersex people in Ireland. Dublin: Gay and Lesbian Equality Network (GLEN) and BeLonG To Youth Services.

King, M., Semlyen, J., Tai, S. S., Killaspy, H., Osborn, D., Popelyuk, D., \& Nazareth, I. (2008). A systematic review of mental disorder, suicide, and deliberate self harm in lesbian, gay and bisexual people. BMC Psychiatry, 8(1), 1-17. doi:10.1186/1471-244x-8-70

Koch, T., \& Harrington, A. (1998). Reconceptualizing rigour: The case for reflexivity. Journal of Advanced Nursing,28(4), 882-890. doi:10.1046/j.1365-2648.1998.00725.x

Larkin, M., Watts, S., \& Clifton, E. (2006). Giving voice and making sense in interpretative phenomenological analysis. Qualitative Research in Psychology,3(2), 102-120. doi:10.1191/1478088706qp062oa 
Lev, A. I. (2004). Transgender emergence: Therapeutic guidelines for working with gender variant people and their families. New York: Haworth Press

Levesque, P. J. (2013). Nurse practitioners knowledge, attitudes, and self-efficacy for working with transgender patients. Clinical Nursing Studies, 1(4). doi:10.5430/cns.v1n4p93

McCann, E. \& Brown, M. (2018). Vulnerability and psychosocial risk factors regarding people who identify as transgender. A systematic review of the research evidence. Issues in Mental Health Nursing (39) 1, 3-15. doi: 10.1080/01612840.2017.1382623

McCann, E., \& Sharek, D. (2013). Survey of lesbian, gay, bisexual and transgender people's experiences of mental health services in Ireland. International Journal of Mental Health Nursing, 23(2), 118-127

McCann, E., \& Sharek, (2015). Metal health needs of people who identify as transgender. Archives of Psychiatric Nursing, 30, 280-285

McCullough, R., Dispenza, F., Parker, L. K., Viehl, C. J., Chang, C. Y., \& Murphy, T. M. (2017). The counselling experiences of transgender and gender nonconforming clients. Journal of Counseling and Development,95, 423-433. doi:10.1002/jcad.12157

McLaughlin, K. A., Hatzenbuehler, M. L., Xuan, Z., \& Conron, K. J. (2012). Disproportionate exposure to early-life adversity and sexual orientation disparities in psychiatric morbidity. Child Abuse \& Neglect, 36(9), 645-655. doi:10.1016/j.chiabu.2012.07.004

McNeil, J., Bailey, L., Ellis, S., \& Regan, M. (2013). Speaking from the Margins. Trans Mental Health and Wellbeing in Ireland. Transgender Equality Network Ireland (TENI).

Paradiso, C., \& Lally, R. M. (2018). Nurse Practitioner Knowledge, Attitudes, and Beliefs When Caring for Transgender People. Transgender Health, 3(1), 48-56. doi: 10.1089/trgh.2017.0048 
Perez-Brumer, A., Day, J. K., Russell, S. T., \& Hatzenbuehler, M. L. (2017). Prevalence and Correlates of Suicidal Ideation Among Transgender Youth in California: Findings From a Representative, Population-Based Sample of High School Students. Journal of the American Academy of Child \& Adolescent Psychiatry,56(9), 739-746. doi:10.1016/j.jaac.2017.06.010

Rachlin, K.(2002). Transgender individuals' experiences of psychotherapy. International Journal of Transgenderism, 6(1).

Rhoades, H., Rusow, J. A., Bond, D., Lanteigne, A., Fulginiti, A., \& Goldbach, J. T. (2018). Homelessness, Mental Health and Suicidality Among LGBTQ Youth Accessing Crisis Services. Child Psychiatry \& Human Development,49(4), 643-651. doi:10.1007/s10578-0180780-1

Smith, J. A., Jarman, M., \& Osborn, M. (1999). Doing interpretative phenomenological analysis in Murray, M. \& Chamberlain, K., Qualitive Health Psychology, Theories and Methods (pp. 218240). London: Sage Publications.

Smith, J. A., Larkin, M., \& Flowers, P. (2009). Doing interpretative phenomenological analysis: A practical guide to method and application. London: SAGE.

Sperber, J., Landers, S., \& Lawerence, S. (2005). Access to health care for transgendered persons: Results of a needs assessment in Boston. International Journal of Transgenderism, 8, 75-91. doi, 10.1300/J485v08n02_08

Strauss, P., Cook, A., Winter, S., Watson, V., Toussaint, D. W., \& Lin, A. (2020). Associations between negative life experiences and the mental health of trans and gender diverse young people in Australia: findings from Trans Pathways. Psychological Medicine, 50(5), 808-817.

The World Professional Association for Transgender Health, (2011). Standards of care for the Health of Transsexual, Transgender and Gender Nonconforming People 7th Version. 
The World Professional Association for Transgender Health

Torres, C. G., Renfrew, M., Kenst, K., Tan-McGrory, A., Betancourt, J. R., \& López, L. (2015). Improving transgender health by building safe clinical environments that promote existing resilience: Results from a qualitative analysis of providers. BMC Pediatrics, 15(1). doi:10.1186/s 12887-015-0505-6

Weir, C., \& Piquette, N. (2018). Counselling transgender individuals: Issues and considerations. Canadian Psychology/Psychologie Canadienne,59(3), 252-261. doi:10.1037/cap0000129. 
Table 1: Participant Information

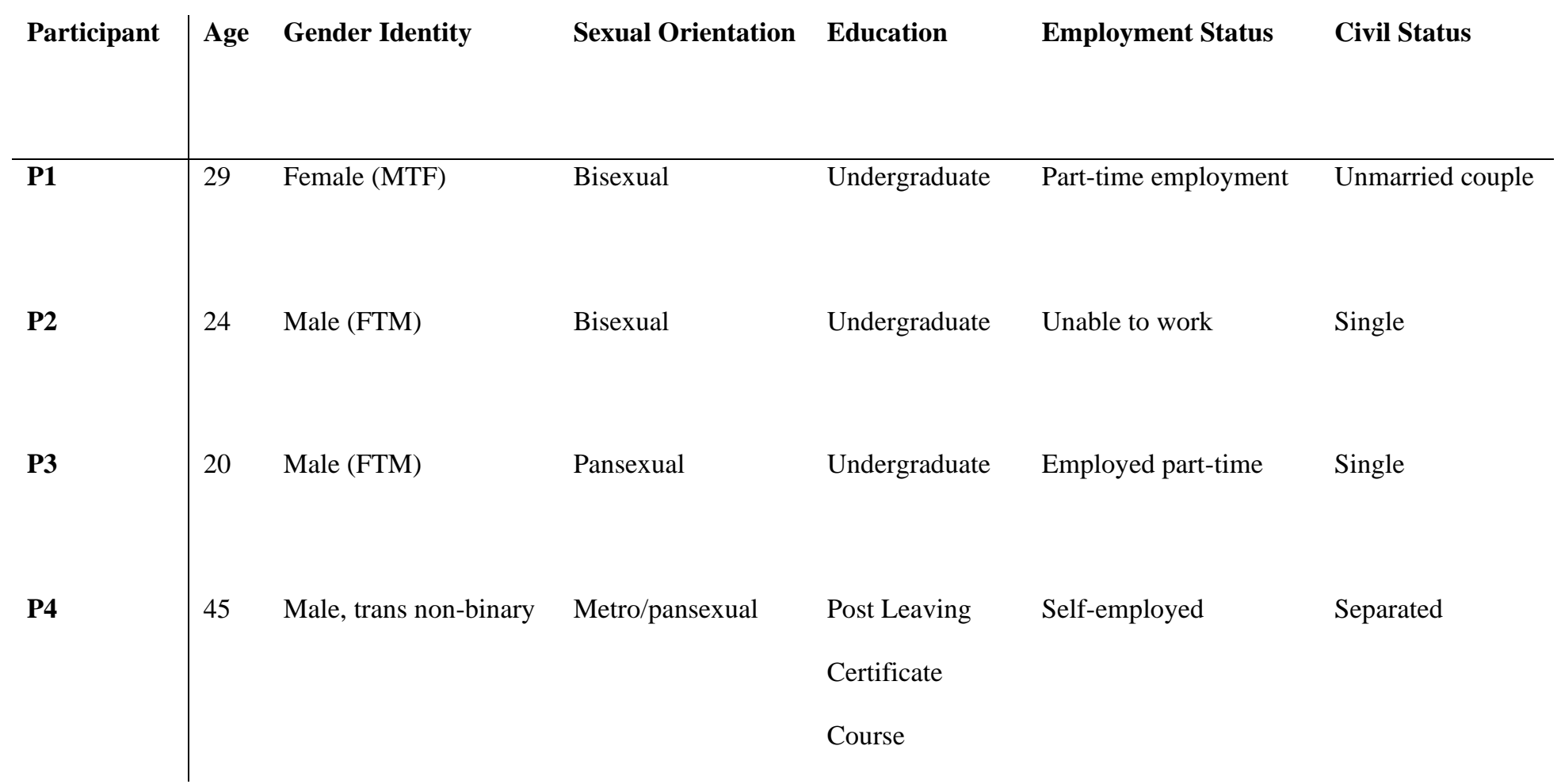

